\title{
Language Strategies in Multinational Corporations: A Cross-Sector Study of Financial Service Companies and Manufacturing Companies
}

\author{
Guro R. Sanden
}

Ph.D. awarded by Copenhagen Business School, Denmark (September 2015)

\section{BIG Question:}

\section{"Do industry sectors matter for corporate language management?"}

\section{Introduction}

As the existence of a common language is a precondition for most types of communication, the question of how multinational corporations (MNCs) manage language and linguistic diversity is something that scholars from different academic disciplines have taken an interest in. Almost two decades have passed since Marschan, Welch and Welch published their 1997 paper titled "Language: The forgotten factor in multinational management", a paper which marks the beginning of a string of language-sensitive research in international business and management. Over the, years a number of studies have examined language and communication in a variety of different organizations and contextual frameworks (see Brannen, Piekkari \& Tietze, 2014; Piekkari \& Tietze, 2011; Piekkari \& Zander, 2005). Indeed, with the increasing focus on language in recent years, one could even argue that as far as international business and management research goes, language is the new culture.

However, the majority of previous studies have been conducted at the level of the firm, thereby paying little attention to how sector-specific differences affect language use and language management practices within firms belonging to different sectors. Situated at the intersection of sociolinguistics and international business and management studies, this thesis focuses on language management in two different industry sectors, namely the financial service sector and the manufacturing sector. Employing a multiple case study design consisting of two matched pair cases, the study examines the means by which language is managed, i.e., language management tools, in four MNCs headquartered in Scandinavia; the two financial service companies Nordea and Saxo Bank and the two manufacturing companies Grundfos and ECCO. The main contribution of this thesis lies in capturing the effect of industry sectors on corporate language management-a level of analysis which has largely been overlooked in previous research.

Financial services and manufacturing are two sectors where sector-specific characteristics could be expected to have an impact on corporate language management. Previous studies have found blue-collar employees to have lower foreign language skills than white-collar employees, which create pressure for multilingual communication in manufacturing companies (Barner-Rasmussen \& Aarnio, 2011). Financial services, on the other hand, are likely to experience a greater external pressure for local language communication, as these companies sell information as part of the service encounter. The interactive customer-company relationship therefore complicates the implementation of a single common corporate language in financial service companies (Luo \& Shenkar, 2006).

The dissertation is guided by two overall research questions. Firstly, how is the context reflected in the way language is managed in the two financial service companies and the two manufacturing companies? Secondly, which language management tools are implemented and why in the two financial service companies and the two manufacturing companies? I answer these questions through a comparative discussion based on document data from the four case companies including e.g., language policies and strategy documents, as well as 46 interviews with managers and employees working with language-related issues in the case companies.

\section{Language Management Tools - An Overview}

The dissertation provides a processual perspective on language strategies by giving emphasis to how these strategies are implemented in practice through various language management tools. Based on a review of the existing literature, the thesis offers a taxonomy of language management tools which presents an overview of the various initiatives the management of a firm may deploy in order to satisfy the company's language needs. These language management tools may be summarised as follows:

Common corporate language: The use of a lingua franca for internal communicative purposes. Can be based on a formal language policy mandate or without a formal language policy.

Multiple corporate languages: The use of multiple languages for internal communicative purposes. Can be based on a formal language policy mandate or without a formal language policy.

Company-specific language: Various ways to control the language of the company either through hard mechanisms such as imposed 
restrictions on vocabulary or syntax rules, or milder mechanisms such as company dictionaries or preferred writing standards.

Language needs analyses: Methodologies to help firms identify the strengths and weaknesses of their organization in terms of foreign language communication.

Interpretation/translation: The use of translation and interpretation services, either through arrangements with external agents or through the establishment of an internal in-house department, or other alternative solutions.

Technological solutions: The use of computer-based technologies to translate text or voice from one language into another.

Language training: Company-funded training programmes to improve the language skills of employees.

Selective recruitment and staffing: Recruitment of language skilled personnel, either full-time, part-time or for a specific period of time, to fill identified language gaps in the company.

Language intermediates: Strategic use of employees who perform a bridging function by virtue of their language competencies, either as part of, or in addition to, their normal job description, or in formal or informal language networks.

\section{The Explanatory Power of Industry Sectors}

Findings from the study reveal that a number of sector-specific factors influence language management at the company level of the four case companies, and that these factors clearly have an impact in terms of which language management tools the companies choose to make use of in their language strategies. In particular, the two financial service companies and the manufacturing companies were found to have three sector-level factors in common, though with somewhat different outcomes. Economic geography increases the use of English for corporate level functions in the two financial service companies owing to the companies' presence in international financial centres. On the other hand, in the two manufacturing companies, this factor increases the need for multiple corporate languages and translation into the mother tongue spoken by the production workers in the industrial locations where English language skills tend to be scarce. In manufacturing, economic geography was also found to lead to the use of language intermediates as mediums of communication. In all case companies, global integration (Prahalad \& Doz, 1987) increases cross-border communication and the use of English for corporate level functions, which also increases selective recruitment of English-skilled employees in both sectors. Industry speak is found to be closely related to company-specific language in all case companies regardless of sector, and technological solutions are implemented in order to manage large term databases in both sectors.

In addition to these factors, the following three sector-specific factors were found in the two financial service companies only: local responsive- ness (Bartlett \& Ghoshal, 1989), in particular with regard to the companies' retail banking operations, enhances the need for local language communication resulting in the use of multiple corporate languages. Local responsiveness also enhances both the use of translation and selective recruitment, while at the same time imposing restrictions on the provision of language training. Age structure of the employees, especially in the retail banking area, creates a need for multiple corporate languages and translation, while reducing the use of language training as a language management tool. Regulatory compliance results in the use of multiple corporate languages and company-specific language, and increases the use of translation and selective recruitment of employees with local language skills.

The following four sector-specific findings were found in the two manufacturing companies only: work environment of production units limits access to technological language management solutions and restricts the amount of language training provided for production workers. Communication mode implies restrictions on the possibility of using written-medium communication directed at production workers with limited literal skills, thereby creating a need to translate information into visual and oral-medium communication. Risk of organizational isolation arises due to few or no direct communication channels between headquarters and foreign subsidiaries, where the use of language intermediates may present a threat to organizational inclusion. Finally, modest to low educational level of production workers increases the need for multiple corporate languages and local language communication through translation, while reducing the provision of language training for this group.

\section{Contributions}

This thesis contributes to the emerging language-sensitive research stream in international business and management by focusing on a level of analysis that is rarely discussed in the existing literature. The thesis demonstrates that industry sector matters: characteristics pertinent to the different sectors clearly hold strong explanatory power when examining in what way the case companies approach language management. The main contribution of this work therefore lies in generating knowledge about sector effects as an important layer of context in the study of corporate language management.

Another contribution of this thesis lies in conceptualising language management through language management tools. Language management tools are defined as the means by which language is managed, i.e., the tools used to address aspects of a company's internal language and communication practices. By placing language management tools next to other forms of management tools, the study shows that it is possible to treat the management of language in the same way as international business and management scholars treat any other aspect of MNC management. The taxonomy of tools provides a framework for operationalizing language management in the management of multinationals. 
At the same time, this thesis also emphasizes that industry sector characteristics affect the companies' use of different language management tools. Clearly, many aspects of a company's context may have an impact on the implementation of such tools, yet, as a cross-sector study, this discussion has focused primarily on how and why the sector matters when it comes to the ways in which companies choose to execute their language management. A contribution of the study therefore lies in calling attention to the strategic considerations that may be explained by sector-specific factors in terms of the selection of different language management tools at company level. This thesis underscores the need to recognize the dynamics of sector effects on corporate language management when examining language management strategically - that is, knowledge and understanding of the sector provides a stronger basis for strategic language management. Thus, in a day-of-age where the study of language has gained momentum in international business and management literature, the present study contributes to make the case for strategic language management as the next frontier in language management research.

In line with what Piekkari, Welch and Welch (2014) describe as "the multilingual reality of global business expansion", the findings show that manufacturing, which is often described as a global industry (e.g., Bartlett \& Ghoshal, 1989), and financial services, which have become increasingly global in the past decades with regard to international trade and investment, are also in need of local-language communication for company-internal reasons. This observation contributes to raise awareness of the role of local languages in global and transnational corporations, where uniform English language policies may be seen as the highway to global efficiency (Neeley, 2011). Global industries, like all other industries, must address a number of factors - including but not limited to the sector-specific factors discussed in this thesis - when managing their internal multilingualism. As a human resource skill, employees' language skills (or lack thereof) create internal pressure for language management and the implementation of language management tools, in particular corporate measures. A strategic approach to language management requires corporate language managers and corporate language management researchers to consider how the language needs of the particular organization can be met in the most efficient manner. The present study thus emphasizes the human resource aspect attached to the management of language.

Furthermore, the dissertation offers rich, in-depth within case analyses of four case companies, two of which have chosen to approach language though detailed language regulation in the form of formalized language policy documents. The thesis offers a processual perspective on how these policies came about, which represents a form of analysis rarely found in language-sensitive research in international business and management. Rather than presenting a picture of how the companies manage language today, the study presents the full story by also considering the development of the language policies as events that offer contextual insight into the companies' current language management practices. The combination of interview data, especially from key informants who took part in developing the companies' language policy documents, combined with the policy documents and other relevant company-specific documents made it possible to examine the different considerations that were made at the time the policies were developed and compare these to the present-day situation.

This study also brings insight into a relationship that has been widely debated in the sociolinguistic literature, namely the relationship between language policy and planning activities at the national (macro) level and at the corporate (meso) level. In line with Kaplan and Baldauf's (1997) theory of linguistic eco-systems, the present study demonstrates that business organizations can be seen as linguistic eco-systems of their own, with multiple company and sector-level forces at work. The implementation of corporate English language policies in countries where English is not an official language, e.g., Scandinavian countries, is occasionally portrayed as a "domain loss" where the national language is perceived to be under threat by increased use of English in business and commerce. However, data from the four case companies show that the introduction of English language policies does not necessarily degrade the status of the national language(s) at the macro (societal) level, given the widespread use of parallel languages, i.e., English via-avis the local language(s).

Finally, a number of findings from this study have direct practical applicability to multilingual organizations. Rather than addressing language and communication-related issues as trivial matters, this study calls for a more strategic approach where managers responsible for language management activities acknowledge the potential of multilingual management. The use of one language management tools does for example not limit the benefits of others. Rather, several language management tools appear to be interconnected and can easily be combined dependent on the company's situation with regard to language and communication practices. What this implies is that the implementation of one language management tool is often insufficient to meet all language needs at all organizational levels. For example, the adoption of an English language policy is likely to trigger the need for follow-up initiatives, such as translation, language training or selective recruitment of language competent personnel. The appropriateness of the various tools is largely dependent on factors pertinent to the company and the company's context, including sector-specific characteristics.

\section{References}

Barner-Rasmussen, W., \& Aarnio, C. 2011. Shifting the faultiness of language: A quantitative functional-level exploration of language use in MNC subsidiaries. Journal of World Business, 46(3): 288-295.

Bartlett, C. A., \& Ghoshal, S. 1989. Managing across borders: The transnational solution. London: Hutchinson. 
Brannen, M. Y., Piekkari, R., \& Tietze, S. 2014. The multifaceted role of language in international business: Unpacking the forms, functions and features of a critical challenge to MNC theory and performance. Journal of International Business Studies, 45(5): 495-507.

Kaplan, R. B., \& Baldauf, R. B. Jr. 1997. Language planning from practice to theory. Clevedon: Multilingual Matters.

Luo, Y., \& Shenkar, O. 2006. The multinational corporation as a multilingual community: Language and organization in a global context. Journal of International Business Studies, 37(3): 321-339.

Marschan, R., Welch, D., \&Welch, L. 1997. Language: The forgotten factor in multinational management. European Management Journal, 15(5): 591-598.

Neeley, T. 2011. Language and globalization: 'Englishnization' at Rakuten. Harvard Business School organizational behavior unit case no. 412-002. Retrieved from http://ssrn.com/abstract=1993062

Piekkari, R., \& Tietze, S. 2011. A world of languages: Implications for international management research and practice. Journal of World Business, 46(3): 267-269.

Piekkari, R., Welch, D. E., \& Welch, L. S. 2014. Language in international business: The multilingual reality of global business expansion. Cheltenham: Edward Elgar.

Piekkari, R., \& Zander, L. 2005. Preface: Language and communication in international management. International Studies of Management and Organization, 35(1): 3-9.

Prahalad, C. K., \& Doz, Y. L. 1987. The multinational mission: Balancing local demands and global vision. New York: The Free Press.

Guro Refsum Sanden (grs.ibc@cbs.dk) is a Postdoctoral Researcher at the Department of International Business Communication at Copenhagen Business School. Her research focuses on the role of corporate language strategies in multinational corporations and the relationship between national language policies and corporate law in Scandinavia. Before entering academia, she held various industry positions, including management trainee in the Danish insurance company Tryg. 